\title{
Status and distribution of Asian elephants in Central Nepal
}

\author{
James L. David Smith and Hemanta R. Mishra
}

Wild elephants currently occur in three populations in the lowlands of Nepal. The eastern and western animals are part of larger populations that extend into India; the central population, estimated to be 21 individuals, is geographically isolated from the other two and confined within Nepal's borders. Tracks of young elephants observed in 1979 and 1989 indicate that reproduction occurs on a regular basis. The present reserve system provides good cover and an excellent food base; the potential for population increase is good. Nepal needs to develop policy to handle human/elephant conflicts so that public support for protection of elephant populations can be maintained.

\section{Introduction}

The Asian elephant Elephas maximus once was distributed from the Tigris-Euphrates in west Asia eastward into the Indian subcontinent, south and South East Asia and Yunnan Province in China. Capture of animals for domestication, sport hunting and habitat fragmentation have been the primary reasons for the decline in wild populations. Currently fewer than 50,000 Asian elephants are confined primarily to forested areas of the Indian subcontinent and South East Asia, occupying a small fraction of their original range (Sukumar, 1989).

In the early nineteenth century elephants occurred across the entire lowland of Nepal (Jerdon, 1874). The current distribution is in three populations (eastern, western, central) that are isolated from each other. The purpose of this paper is to report the status of the central population and to summarize unpublished anecdotal information on the other populations.

\section{Historical perspective}

The decline of elephants in Nepal did not occur until the twentieth century. Shooting of elephants for sport was never very common in Nepal because of the symbolic role of the elephant as the god Ganesh (B.B. Shah, pers. comm.). Although capture of elephants for domestication in India dates to at least 2000BC (Clutton-Brock, 1987), it was not extensive in Nepal's lowlands until the late 1800s-early 1900 s. During this period, however, demand for elephants for royal hunts was probably a major factor reducing wild populations. Smythies (1942) reported that up to 315 animals were used in the 1930s in a single royal hunt in what is now Royal Chitwan National Park.

In the 1920s the Char Kosha Jhare, a continuous belt of lowland forest famous for its abundant wildlife, stretched the entire length of Nepal. At that time elephants were found in every district of the Nepalese lowlands (B.B. Shah, pers. comm.). By the end of World War II, the Char Kosha Jhare was gradually fragmented and elephant numbers had begun to decline ( $R$. Lothan, pers. comm.). However, in the 1950 s, a malaria eradication and transmigration programme resettled people from the middle hills into the lowlands; these activities resulted in extensive habitat loss and fragmentation that permanently altered the landscape 
of this region (Rose, 1971; Smith et al., 1987). Since the initiation of this programme, it is estimated that there has been a 50 per cent decline in the extent of forest cover in the lowlands (UNDP/World Bank, 1983). It appears that capture of elephants for domestication kept pace with habitat destruction because there was never a period when remnant populations depended primarily on agricultural lands for their food. Despite establishment of a comprehensive park and reserve system in the 1970s (Upreti, 1985) the distribution of elephants does not appear to be expanding.

\section{Methods}

Information on the status of the central population was acquired in February-March 1989 in Parsa Wildlife Reserve and Bara Forest District. Data on number of individuals per group, size of individuals and number of males (visible tusks) were obtained from direct observations of elephants or their tracks and from interviews with local villagers, forest guards and wildlife officials. Reports on group size were validated by comparing responses of people who observed elephants during a 2week grass-cutting period (Mishra, 1982) in late January 1989 when thousands of people were in the forest. We also include information acquired during several shorter visits to the Parsa area in 1979 and 1980.
Information on Nepal's eastern and western elephant populations was obtained during several visits to these areas in 1977 and 1984 (eastern Nepal) and 1980 and 1987 (western Nepal) and from conversations with wildlife biologists and forest officers. Because there has been no systematic reporting of information on wild elephants in Nepal, we include this information here.

To document recruitment in the central population, we measured the length of all distinct rear-foot tracks we found. These measurements then were compared to measurements obtained from known-age elephants born at the elephant breeding facility, Sauraha, Royal Chitwan National Park. This system of ageing was more appropriate to our situation than the traditional method employed by elephant drivers (shoulder height computed as twice the circumference of the forefoot; Budi Lal Tharu, pers. comm.) or the system used by Sukumar (1989), which requires viewing the animal near a measuring staff. Age-class definitions used were as follows: calf ( $0-1$ year), juvenile ( $1-5$ years), subadult ( $5-15$ years) and adult (15+ years) (Sukumar, 1989).

\section{Distribution and status of the central elephant population}

Three populations of elephants currently occur in Nepal (Figure 1). The elephants in

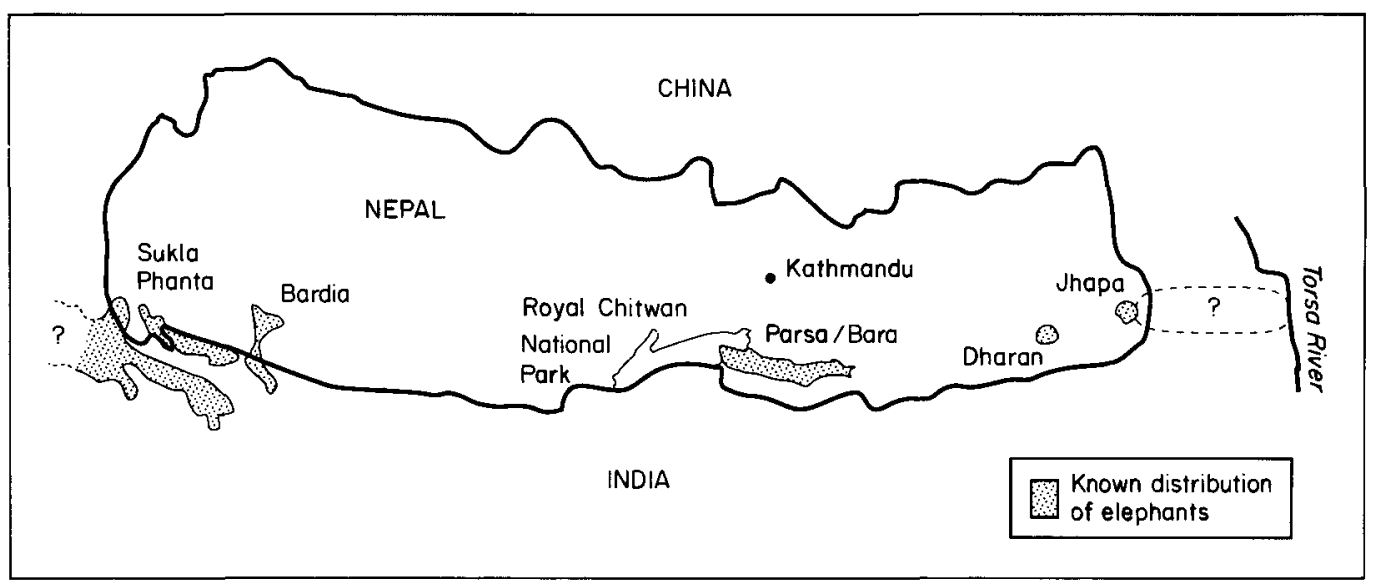

Figure 1. Current distribution of wild elephants in Nepal. 
eastern and western Nepal are part of larger populations extending into India; the central population is a small population that is geographically isolated from the other two and confined within Nepal's borders.

Elephants are observed throughout the year in the vicinity of Ram Bhori and Bhatta, which are small villages within the Parsa Wildlife Reserve in central Nepal. These elephants have also been seen crossing the HetaudaBirgunj highway $17 \mathrm{~km}$ east of the villages and at Hal Khoriya Daha (a small lake) a further $8 \mathrm{~km}$ east. Occasionally tracks and dung have been found $11 \mathrm{~km}$ west of Ram Bhori along the Shikaribas Khola and as far north as the base of the Churia Hills. We estimate the population utilizes an area of approximately $800 \mathrm{sq} \mathrm{km}$, but their range may be considerably larger.

A maximum of 21 elephants was observed during the grass-cutting season in January 1989. Villagers who observed these animals reported that there were three adult males. At other times of the year these same animals have been observed as two groups, of eight and 13 animals.

Measurements of rear tracks of three young in a group of seven animals were 19, 22, and $27 \mathrm{~cm}$. Based on rear-foot size of eight knownage domestic calves and juveniles the approximate age of two of the wild animals was 1 and 3 years (Figure 2). When we measured tracks in 1979 two animals also were estimated to be 1 and 3 years. Inhabitants of Ram Bhori and

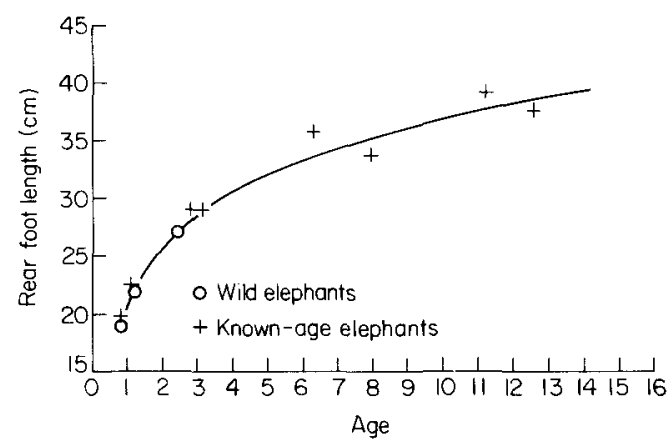

Figure 2. Comparison of wild elephant track measurements to domestic track measurements from known-age animals. The curve is the regression equation, $y=20.71+16.36 * \log (x)$.
Bhatta who observed the elephants in 1989 said that, in addition to these very young animals, there were several subadults that were approximately one-half to three-quarters the height of adults.

During the dry season water sources are limited to the vicinity of Ram Bhori and Bhatta villages in the west and Hal Khoriya Daha in the east. The only other sources of water are four stream beds at the base of the deeply eroded Churia Hills. These streams become dry within $0.5 \mathrm{~km}$ of the base of the hills and remain dry for $5-8 \mathrm{~km}$. The lack of other nearby sources of water and the loss of migratory traditions probably keep this population localized.

\section{Distribution of eastern and western populations}

The elephants in eastern Nepal are not permanent residents; animals regularly migrate from India by crossing $5 \mathrm{~km}$ of cultivation on the Nepal side of the border to reach forest cover near Jhapa. Elephants have been migrating to this site from India as long as local villagers can remember. It is approximately $300 \mathrm{~km}$ east of the central population. In November 1977 50 elephants remained in Nepal for about 2 weeks. During this time they fed almost exclusively in rice fields and damaged 167 houses and killed four people. Five elephants were shot and the following day 45 animals were counted as they passed though several villages on their return to India. In 1984 Mishra visited this same area and counted 15 animals; five remained in Nepal. These are probably the elephants that were recently sighted at Dharan (J. Heinen, pers. comm.). Elephants that migrate to Nepal are probably part of the population of approximately 80 individuals that travel as far east as the west side of the Torsa River (120 km east of Jhapa) along the western Bengal and Bhutan border (Sukumar, 1989).

Two groups of elephants occur in western Nepal. Evidence suggests they probably are from the same population. These groups occur in the vicinity of Royal Bardia Wildlife 
Reserve, approximately $370 \mathrm{~km}$ west of the central population, and Sukla Phanta, a further $104 \mathrm{~km}$ west of the Bardia area. There have been no systematic surveys of elephants in western Nepal but individuals and their tracks have been sighted on a regular basis over the past 18 years by the warden of Royal Bardia Wildlife Reserve (K. M. Shresta, pers. comm.). Individuals range south along the Karnali River from the Reserve to a patch of riverine forest across the border in India. These elephants may be part of a population of approximately 25 animals in Dudhwa National Park, India (Sukumar, 1989). Although elephants along the Karnali River are separated from forests adjacent to Dudhwa by a strip of treeless, intensively cultivated land $7.5 \mathrm{~km}$ wide, elephants often cross similar distances elsewhere. An exceptionally large male has been seen in Bardia and Sukla Phanta Wildlife Reserve (P. Byrne, pers. comm.) indicating that there is migration between these populations. Although there have been no surveys of the area in India adjacent to Sukla Phanta, elephants in Sukla Phanta are thought to be part of a large population of about 500 animals extending to Corbett National Park in India (Sukumar, 1989).

\section{Conclusions}

We suggest that the elephant population in central Nepal may be increasing. The highest count of elephants between 1979 and 1980 was 13 animals; in 1989 the estimate was 21 individuals. Tracks of individuals less than 3 years of age were observed in both 1979 and 1989, indicating that reproduction occurs on a regular basis. Using a density estimate of 0.25 elephants/sq $\mathrm{km}$, which is approximately half that reported by Sukumar (1989), we estimate that the area currently occupied by elephants has a minimum carrying capacity of at least 200 animals. Royal Chitwan National Park has $492 \mathrm{sq} \mathrm{km}$ of good quality elephant habitat (for example, on alluvial or gently sloping terrain) and the Park north of the Churia Hills already supports a population of more than 80 domestic elephants belonging to the National Park, the Nepal Conservation and Research Training Center, and five tourist concessions (Santiapillai, 1987).

Because the present reserve system provides good cover and an excellent food base, it is important to examine the ecological and socioeconomic consequences of an increasing elephant population. A vegetation monitoring system is needed to determine the current impact of domestic and wild elephant browsing on native vegetation and to predict vegetation changes that will occur if domestic or wild elephant populations increase in the future.

Planning for increased human/elephant conflict is equally important. In central Nepal the contiguous suitable habitat for elephants $(1300 \mathrm{sq} \mathrm{km})$ is large enough to support a population that is not dependent on surrounding cultivation. However, crop depredation by 21 elephants currently occurs in Ram Bhori and Bhatta and it is certain to increase if numbers of elephants increase. When elephants occupy forested areas adjacent to villages, raiding of crops is part of their typical foraging behaviour (Sukumar, 1990). In the vicinity of Ram Bhori and Bhatta, crop depredation primarily is confined to the dry season (March-April) when elephants feed on irrigated crops. One solution to localized crop destruction is erection of temporary or permanent electric fences during the season when raiding is likely to occur (Blair et al., 1979). To maintain public support for protection of the elephant population in central Nepal, wildlife officials must develop a policy to handle crop depredation problems and allocate resources to implement the policy. Ultimately the people of Nepal must weigh the value of maintaining a viable indigenous elephant population as a symbol of their country's biological, cultural and religious heritage against short-term demands for rapid development.

\section{Acknowledgments}

We thank His Majesty's Royal Government of Nepal for permission to work in Nepal and the staff of the Terai Ecology Project for help collecting data. F. Cuthbert, J. Heinen and C. Wemmer commented on 
an earlier draft of the manuscript. This study was done while the authors were supported by Earthwatch, Smithsonian Institution, the University of Minnesota Agricultural Experiment Station, and World Wildlife Fund.

\section{References}

Blair, J.A.S., Boon G.G., and Noor, N.M. 1979. Conservation or cultivation: the confrontation between the Asian elephant and land development in peninsular Malaysia. Land Development Digest, 2, 27-59.

Clutton-Brock, J. 1987. A Natural History of Domesticated Mammals. University of Texas Press, Austin.

Jerdon, T.C. 1874. The Mammals of India. John Whelden, London.

Mishra, H.R. 1980. Status of the Asian elephant in Nepal. In The Status of the Asian Elephant in the Indian Sub-continent. IUCN/SSC Asian Elephant Group. Bombay Natural History Society, Bombay, India.

Mishra, H.R. 1982. Balancing human needs and conservation in Nepal's Royal Chitwan Park. Ambio, 11, 246-251.

Rose, L.E. 1971. Nepal: Strategy for Survival. Oxford University Press, Oxford, England.

Santiapillai, C. 1987. The status, distribution and conservation of elephants in Nepal. Unpubl. rep. of the IUCN/SSC Asian Elephant Specialist Group, Gland, Switzerland.

Smith, J.L.D., Mishra, H.R. and Wemmer, C. 1987. A conservation strategy for tigers. In Tigers of the World: the Biology, Biopolitics, Management and Conservation of an Endangered Species (eds R.L. Tilson and U.S. Seal), Noyes Publ., Park Ridge, NJ.

Smythies, E.A. 1942. Big Game Shooting in Nepal. Thacker, Spink and Co., Calcutta.

Sukumar, R. 1989. The Asian Elephant: Ecology and Management. Cambridge University Press, Cambridge.

Sukumar, R. 1990. Ecology of the Asian elephant in southern India II. feeding habits and crop raiding patterns. J. Trop. Ecol. 6, 33-53.

UNDP/World Bank. 1983. Nepal: Issues and Options in the Energy Sector. UNDP/World Bank Report No. 4474-NEP.

Upreti, B. 1985. The development of a protected area system in Nepal. In Conserving Asia's Natural Heritage: the Planning and Management of Protected Areas in the Indomalayan Realm (ed J.W. Thorsel), IUCN, Gland, Switzerland.

James L. David Smith, Department of Fisheries and Wildlife, 1980 Folwell Ave., University of Minnesota, St. Paul, MN 55108, USA.

Hemanta R. Mishra, King Mahendra Trust for Nature Conservation, Box , Kathmandu, Nepal. 